OPEN ACCESS

Edited by:

Fan Zhang,

Fudan University, China

Reviewed by: Xian Chen,

Shenzhen University, China Jingsan $X u$

Queensland University of Technology, Australia

*Correspondence: Jianping Yang jianpingyang@dhu.edu.cn Wei Luo

wluo@dhu.edu.cn

tThese authors have contributed equally to this work

Specialty section:

This article was submitted to Nanoscience,

a section of the journal

Frontiers in Chemistry

Received: 26 November 2018 Accepted: 01 April 2019

Published: 18 April 2019

Citation:

Xu H, Gao J, Li M, Zhao Y, Zhang M, Zhao T, Wang L, Jiang W, Zhu G,

Qian X, Fan Y, Yang J and Luo W (2019) Mesoporous $\mathrm{WO}_{3}$ Nanofibers With Crystalline Framework for High-Performance Acetone Sensing. Front. Chem. 7:266 doi: 10.3389/fchem.2019.00266

\section{Mesoporous $\mathrm{WO}_{3}$ Nanofibers With Crystalline Framework for High-Performance Acetone Sensing}

\author{
Haiyun Xu ${ }^{1 \dagger}$, Jie Gao ${ }^{1 \dagger}$, Minhan $\mathrm{Li}^{1}$, Yuye Zhao ${ }^{1}$, Ming Zhang ${ }^{2}$, Tao Zhao ${ }^{1}$, Lianjun Wang ${ }^{1}$ \\ Wan Jiang ${ }^{1,3,4}$, Guanjia Zhu ${ }^{1}$, Xiaoyong Qian ${ }^{1}$, Yuchi Fan ${ }^{3}$, Jianping Yang ${ }^{1,3 *}$ and \\ Wei Luo ${ }^{1,3 *}$ \\ ${ }^{1}$ State Key Laboratory for Modification of Chemical Fibers and Polymer Materials, College of Materials Science and \\ Engineering, Donghua University, Shanghai, China, ${ }^{2}$ Materials Genome Institute, Shanghai University, Shanghai, China, \\ ${ }^{3}$ Institute of Functional Materials, Donghua University, Shanghai, China, ${ }^{4}$ School of Materials Science and Engineering, \\ Jingdezhen Ceramic Institute, Jingdezhen, China
}

Semiconducting metal oxides with abundant active sites are regarded as promising candidates for environmental monitoring and breath analysis because of their excellent gas sensing performance and stability. Herein, mesoporous $\mathrm{WO}_{3}$ nanofibers with a crystalline framework and uniform pore size is successfully synthesized in an aqueous phase using an electrospinning method, with ammonium metatungstate as the tungsten sources, and $\mathrm{SiO}_{2}$ nanoparticles and polyvinylpyrrolidone as the sacrificial templates. The obtained mesoporous $\mathrm{WO}_{3}$ nanofibers exhibit a controllable pore size of $26.3-42.2 \mathrm{~nm}$, specific surface area of 24.1-34.4 $\mathrm{m}^{2} \mathrm{~g}^{-1}$, and a pore volume of $0.15-0.24 \mathrm{~cm}^{3} \mathrm{~g}^{-1}$. This unique hierarchical structure, with uniform mesopores and interconnected channels, could facilitate the diffusion and transportation of gas molecules in the framework. Gas sensors, based on mesoporous $\mathrm{WO}_{3}$ nanofibers, exhibit an excellent performance in acetone sensing with a low limit of detection ( $<1 \mathrm{ppm})$, short response-recovery time (24 s/27 s), a linear relationship in a broad range, and good selectivity.

Keywords: mesoporous materials, $\mathrm{WO}_{3}$, nanofibers, electrospun, acetone, sensor

\section{INTRODUCTION}

Over the past few decades, the precise monitoring of toxic polluting gases has attracted great attention in modern society in environmental protection, industrial production, health care, and so forth (Kawano et al., 2007; Wang et al., 2007; Salehi et al., 2014). Acetone is a common type of reagent which is frequently used in manufacturing industries and laboratories (Zhang et al., 2017). As a highly toxic gas, acetone is harmful to human health, and long-term exposure to acetone may cause irritation and damage to the eyes, nose, and central nervous system (Jia et al., 2014). In addition, acetone concentrations in respiration can be characterized as a biomarker in the rapid diagnosis of diabetes, because acetone concentrations exhaled from diabetes patients $(1.8 \mathrm{ppm})$ are much higher than in a healthy individual (0.3-0.9 ppm) (Singkammo et al., 2015; Zhou et al., 2018). Therefore, it is of great interest and importance to develop acetone sensors with a low detection limit, fast response recovery dynamics, high sensitivity and selectivity. Among a variety of sensing-active materials used for the detection of acetone, metal oxide semiconductors $\left(\mathrm{WO}_{3}, \mathrm{TiO}_{2}, \mathrm{SnO}_{2}, \mathrm{ZnO}\right.$, $\mathrm{Fe}_{2} \mathrm{O}_{3}$, etc.) have been considered as appealing candidates due to their remarkable sensitivity, 
low cost, and excellent stability (Wang et al., 2010; Luo et al., 2013; Kim and Lee, 2014; Zhu et al., 2017a; Zhou et al., 2018). The sensing mechanism of semiconducting metal oxides (SMOs)-based sensors is widely accepted to be the change in conductivity when exposed in specific gas. The adsorbed gaseous analytes may cause an increase or decrease in the resistance of semiconducting metal oxides (Barsan and Weimar, 2001; Yamazoe et al., 2003; Qiu et al., 2018; Zhang Q. et al., 2018). Given that the gas-sensing process involves the adsorption-desorption and catalytic reactions on the surface of the metal oxides, a rational design and controllable synthesis of nanomaterials with high surface areas, abundant active sites, tailor-designed nanostructures and outstanding catalytic performance, are considered as promising approaches to enhance the sensing performance of the semiconducting metal oxides.

Mesoporous semiconducting metal oxides (MSMOs), as an important category of nanostructured materials, have drawn much attention because of their high surface area, uniform pore size, highly crystalline framework, numerous active sites, interconnected pore structure and large pore size. The high surface area and abundant active sites greatly facilitates the interaction between metal oxide frameworks and gaseous molecules, as well as surface catalytic reactions. In addition, the large porosity and well-connected mesostructure favors rapid and effective diffusion of gas molecules (Li et al., 2014; Luo et al., 2016b; Ma et al., 2018). Therefore, MSMOs are regarded as promising candidates for gas sensing. To date, various MSMOs have been synthesized through different approaches, such as sol-gel processes, spray pyrolysis, chemical vapor deposition and precipitation reactions (Du et al., 2011; Luo et al., 2016a; Zhao et al., 2016; Channei et al., 2018; Jha G. et al., 2018; Zhang Y. et al., 2018). However, these methods usually give rise to an uncontrolled morphology and low porosity, which is not favorable for sensing performance. Additionally, a lot of work has been focused on the design and construction of various nanostructures of SMOs to improve the their sensing performance, including zero-dimensional nanoparticles (NPs) (Yang Z. et al., 2018; Zhang H. et al., 2018; Zhao et al., 2019), one-dimensional nanofibers (NFs) (Saha and De, 2013; Kim et al., 2016a; Ren et al., 2016; Nada et al., 2017; He et al., 2018; Jeong et al., 2018) and nanowires (NWs) (Wang et al., 2004; Rakhi et al., 2012; Dam and Lee, 2013; Chen et al., 2015; Li X. et al., 2017), two-dimensional nanosheets (Wang et al., 2016, 2017; Li F. et al., 2017; Kaneti et al., 2018) and membranes (Dasog et al., 2012; Barr et al., 2017; Jha G. et al., 2018; Wang W. Q. et al., 2018). Nanofibers have drawn particular attention due to their exceptionally high surface area-to-volume ratio, high porosity, superior surface permeability and accessibility, making them an attractive candidate for gas sensing (Guo et al., 2014; Jha R. K. et al., 2018; Yan et al., 2018). Electrospinning technology has been demonstrated as an effective approach to prepare micro-sized and nano-sized fibers. The structure, morphology and dispersion of functional components of the fibers synthesized by electrospinning can be well-tailored through well-controlled conditions and compositions (Wang and Hashimoto, 2018; Yoon et al., 2018; Zhang D. et al., 2018). Kim et al. fabricated semiconducting metal oxide nanofibers through a protein nanocage templating route, to detect trace amounts of target biomarkers in exhaled breath (Kim et al., 2016a). Nevertheless, up to now, it remains a great challenge to construct mesoporous structures in nanofibers with controllable pore size and morphologies, which is highly desirable for improved gas sensing performance.

Among various SMOs, tungsten oxide $\left(\mathrm{WO}_{3}\right)$, an $n$-type semiconductor with a band-gap of $2.5 \mathrm{eV}$, is a promising sensing material for the detection of gas due to its variable oxidation states and suitable band structure (Wang C. Y. et al., 2018). Herein, we adopt a facile approach based on electrospinning to synthesize mesoporous $\mathrm{WO}_{3}$ nanofibers (NFs) with uniform and controllable pore sizes using $\mathrm{SiO}_{2}$ nanoparticles and polyvinylpyrrolidone (PVP) as sacrificial templates, ammonium paratungstate as a tungsten precursor and water as a solvent. Due to the support of the rigid PVP species during electrospinning process, the interconnected porous structure and unique fiberlike morphology can be well-maintained after calcination in nitrogen and air, followed by treatment with hydrofluoric acid selectively etched silica particles, creating uniform mesopores in the nanofibers. The obtained mesoporous $\mathrm{WO}_{3} \mathrm{NFs}$ have crystalline frameworks, large uniform pore sizes of $26.3 \mathrm{~nm}$ and $42.2 \mathrm{~nm}$, and their specific surface area and pore volume can be as high as $34.4 \mathrm{~m}^{2} / \mathrm{g}$ and $24.1 \mathrm{~cm}^{3} / \mathrm{g}$, respectively. Moreover, the mesoporous $\mathrm{WO}_{3} \mathrm{NFs}$ based sensors exhibit superior gas sensing performance with a fast response (24s) and recovery $(27 \mathrm{~s})$, high sensitivity of $23\left(R_{\mathrm{a}} / R_{\mathrm{g}}\right)$ at $50 \mathrm{ppm}$ when operating at $300^{\circ} \mathrm{C}$, an ultralow limit of detection of $1 \mathrm{ppm}$, and good selectivity, which contributes to their good merits of suitable pore size, high surface area and abundant active sites located on the surface, and continuous and crystalline framework with open pore channels. Such an excellent sensing performance opens up the possibility for the mesoporous $\mathrm{WO}_{3} \mathrm{NFs}$ based sensor to be used in many fields such as environmental monitoring and in the rapid diagnosis of disease.

\section{EXPERIMENTAL SECTION}

\section{Chemicals and Materials}

Tetraethyl orthosilicate (TEOS), ethanol, $\mathrm{NH}_{4} \mathrm{OH}$ solution and hydrofluoric acid of AR grade were purchased from SinoPharm Chemical Reagent Co. Ltd. Polyvinylpyrrolidone (PVP, $\mathrm{M}_{\mathrm{W}} \approx 40,000 \mathrm{~g} / \mathrm{mol}$ ) was purchased from Aldrich. Ammonium metatungstate hydrate $\left[\left(\mathrm{NH}_{4}\right)_{6} \mathrm{H}_{2} \mathrm{~W}_{12} \mathrm{O}_{40} \cdot \mathrm{xH}_{2} \mathrm{O}, 99.5 \%\right.$ metals basis] was purchased from Aladdin.

\section{Preparation of $\mathrm{SiO}_{2} \mathrm{NPs}$}

The $\mathrm{SiO}_{2}$ NPs with different diameters was prepared using a base catalyzed sol-gel method previously reported (Dasog et al., 2012). Typically, TEOS $(10 \mathrm{~mL})$ was dissolved in a solvent mixture of ethanol $(10 \mathrm{~mL})$, deionized water $(20 \mathrm{~mL})$ and $\mathrm{NH}_{4} \mathrm{OH}$ solution (42\%, $5 \mathrm{~mL}$ ). The obtained solution was further stirred for 1 or $2 \mathrm{~h}$ to yield different size $\mathrm{SiO}_{2}$ NPs. The white precipitate was collected by vacuum filtration and washed with deionized water four times. The solid was transferred to an oven and was kept there for $24 \mathrm{~h}$ at $100^{\circ} \mathrm{C}$ to remove any residual water and ethanol. 
A

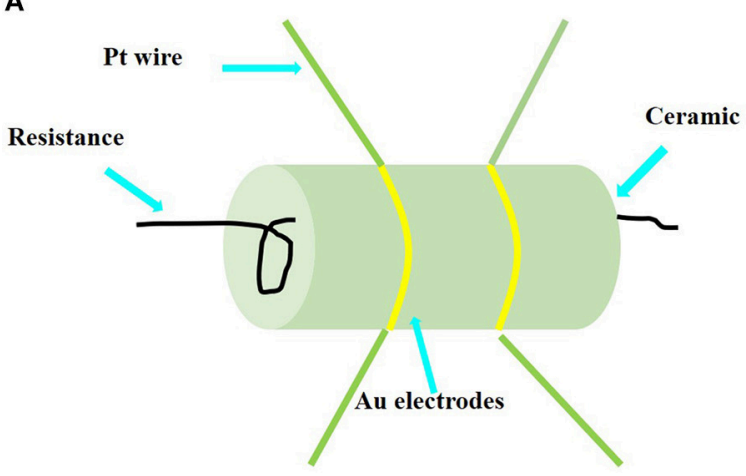

B

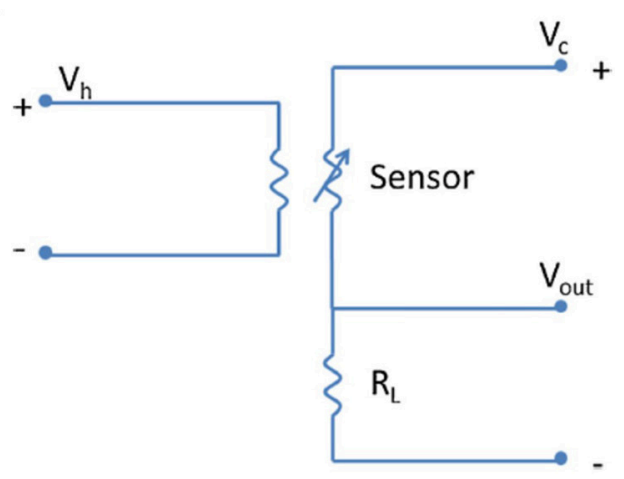

FIGURE 1 | (A) Sketch of the structure of the side-heated mesoporous $\mathrm{WO}_{3} \mathrm{NFs}$ based gas sensor. (B) Electric circuit of gas sensing measurements.

\section{Synthesis of Mesoporous $\mathrm{WO}_{3} \mathrm{NFs}$}

Typically, mesoporous $\mathrm{WO}_{3}$ NFs were synthesized through an electrospinning method as follows: $\left(\mathrm{NH}_{4}\right)_{6} \mathrm{H}_{2} \mathrm{~W}_{12} \mathrm{O}_{40} \cdot \mathrm{xH}_{2} \mathrm{O}$ $(2.7 \mathrm{~g})$ and PVP $(3.0 \mathrm{~g})$ was dissolved in deionized water $(4 \mathrm{~mL})$. This was followed by the addition of $\mathrm{SiO}_{2} \mathrm{NPs}(0.035 \mathrm{~g})$ with a diameter of $25 \mathrm{~nm}$. Then, the solution was stirred for $20 \mathrm{~h}$ for further electrospinning. The as-prepared gel was loaded into a plastic syringe and connected to a high voltage power supply for electrospinning. Twenty kilovolts high voltage was applied between the spinneret and the collector in a gap of $15 \mathrm{~cm}$. In this way, hybrid precursor nanofibrous membranes were obtained. Then, the as-made products were heated with a ramp of $1^{\circ} \mathrm{C} \mathrm{min}{ }^{-1}$ to $350^{\circ} \mathrm{C}$ for $3 \mathrm{~h}$ in nitrogen, resulting in the carbon-supported amorphous tungsten oxide powders. The carbon species was removed and crystallization of the amorphous tungsten oxide frameworks was carried by subsequent heat treatment with a ramp of $1^{\circ} \mathrm{C} \mathrm{min}^{-1}$ to $500^{\circ} \mathrm{C}$ in air for another $1 \mathrm{~h} . \mathrm{SiO}_{2} \mathrm{NPs}$ was completely removed from the composites by treatment with a HF solution (5 wt\% aqueous solution, $8 \mathrm{~mL}$ ) for $2 \mathrm{~h}$ and subsequently washed with deionized water and ethanol. Finally, the obtained sample was denoted as mesoporous $\mathrm{WO}_{3}-25$ NFs. Through the same approach, silica NPs with larger diameters $(\sim 40 \mathrm{~nm})$ were also used as a hard template to synthesize mesoporous $\mathrm{WO}_{3} \mathrm{NFs}$, and the obtained samples were denoted as mesoporous $\mathrm{WO}_{3}-40 \mathrm{NFs}$. Control experiments, without addition of $\mathrm{SiO}_{2} \mathrm{NPs}$, were performed according to the same method and procedure, and the obtained sample was denoted as a non-mesoporous $\mathrm{WO}_{3} \mathrm{NFs}$.

\section{Measurement and Characterization}

Field-emission scanning electron microscopy (FE-SEM) was operated on a Hitachi S4800 (Japan) field-emission scanning electron microscope. Transmission electron microscopy (TEM) was conducted on a JEM-2100 F at an accelerating voltage of 200 $\mathrm{kV}$. Wide-angle X-ray diffraction (XRD) patterns were collected on a Rigaku D/Max-2550 PC diffractometer (Tokyo, Japan) in the $2 \theta$ range of $10-90^{\circ}$. Nitrogen sorption isotherms were measured at $77 \mathrm{~K}$ with a Micromeritics Tristar 3020 analyzer (USA). Before measurements, the samples were degassed under vacuum at $180^{\circ} \mathrm{C}$ for at least $6 \mathrm{~h}$. The Brunauer-Emmett-Teller (BET) method was utilized to calculate the specific surface areas using the adsorption data at $P / P_{0}=0.02-0.20$. The pore size distribution (PSD) was calculated from the adsorption branch using the Barrett-Joyne-Halenda (BJH) model. The total pore volume $\left(\mathrm{V}_{\text {total }}\right)$ was estimated from the adsorbed amount at $P / P_{0}$ $=0.995$. The XPS were collected on an RBD 147 upgraded PHI 5000C ESCA system with a dual X-ray source. The Mg Ka $(1253.6 \mathrm{eV})$ anode and a hemispherical energy analyzer were used in the measurements. All of the binding energies were referenced to the $\mathrm{C} 1 \mathrm{~s}$ peak at $284.8 \mathrm{eV}$ of the surface adventitious carbon.

\section{Gas Sensing Performance}

Side-heated gas sensors were prepared using a similar method reported previously (Zhang et al., 2009). The mesoporous (or non-mesoporous) $\mathrm{WO}_{3}$ NFs was mixed with deionized (DI) water and ground in an agate mortar to form a paste. The mass ratio of mesoporous (or non-mesoporous) $\mathrm{WO}_{3} \mathrm{NFs}$ to DI water in the paste is 7:3. The paste was coated on an alumina ceramic tube printed with a pair of Au electrodes, and the thickness of the paste membrane was about $300 \mu \mathrm{m}$. Subsequently, the coated alumina ceramic tube was dried at room temperature for $24 \mathrm{~h}$ and then annealed at $300^{\circ} \mathrm{C}$ for $2 \mathrm{~h}$ with a ramping rate of $5^{\circ} \mathrm{C} / \mathrm{min}$ in air. Then, a Ni-Cr alloy wire was inserted into the tube as a heater, and the working temperature could be adjusted by changing the heating voltage. Furthermore, the obtained sensor was kept at the optimal working temperature for a week before measurement to further improve the long-term stability. The assembled sensing device is depicted in Figure 1A. The stationary state gas distribution method was applied for testing the gas response. In the electric circuit for measuring the gas response (Figure 1B), a load resistor $\left(R_{\mathrm{L}}\right)$ was connected in series with a gas sensor. The circuit voltage $\left(V_{C}\right)$ was set at $5 \mathrm{~V}$ and the output voltage $\left(V_{\text {OUT }}\right)$ was the terminal voltage of the load resistor. Test gases (such as acetone, methanol, ethanol, toluene, formaldehyde) were injected into a test chamber and diluted with air. The gas response of the sensor is defined as $S$ $=R_{\mathrm{a}} / R_{\mathrm{g}}$ (for reducing gases) or $S=R_{\mathrm{g}} / R_{\mathrm{a}}$ (for oxidizing gases), where $R_{\mathrm{a}}$ is the sensor resistance in air and $R_{\mathrm{g}}$ is that in the 


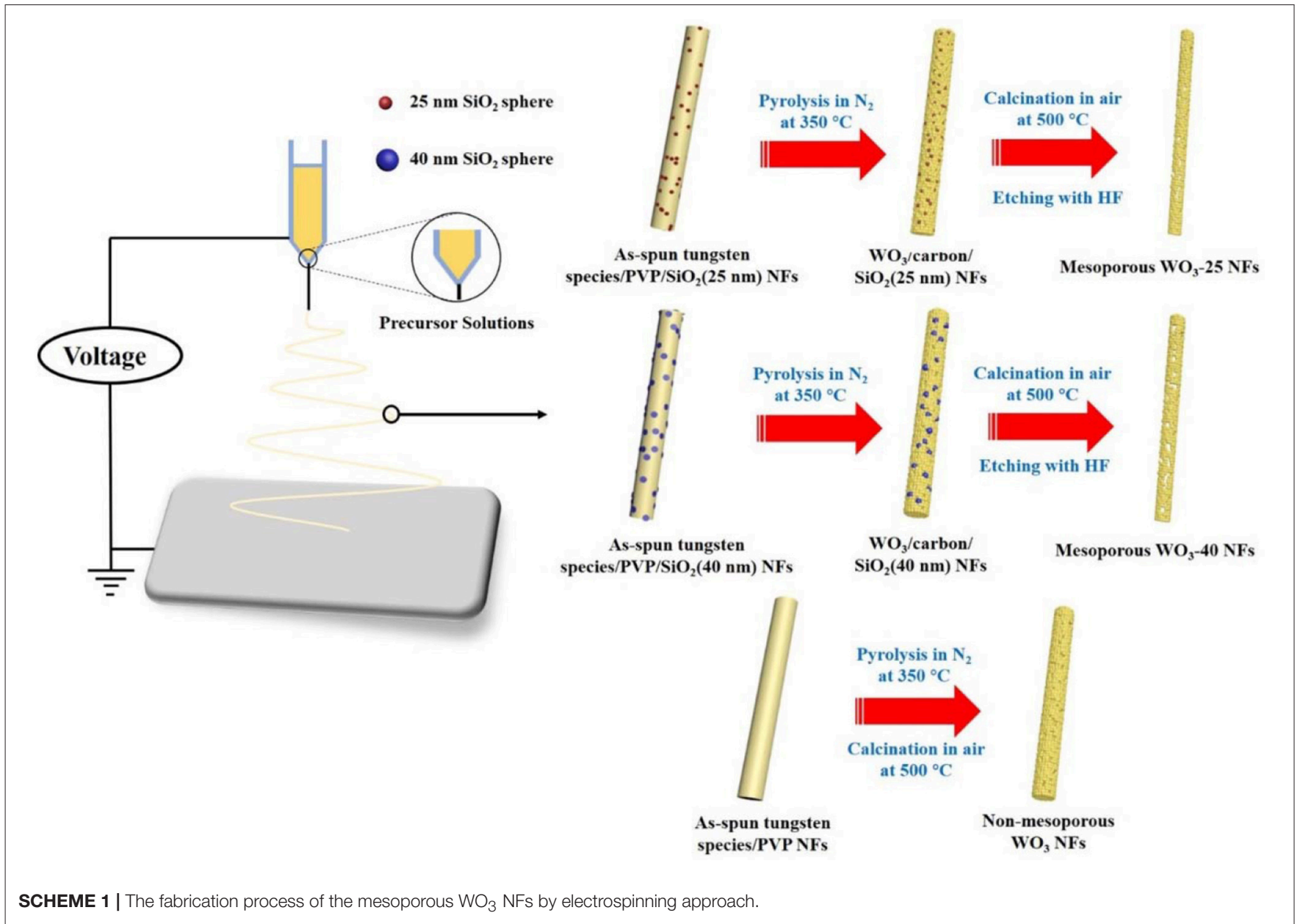

gas tested. The response time is defined as the time taken for the variation in conductance to reach $90 \%$ of the equilibrium value after a test gas was injected, and the recovery time is the time taken for the sensor to return to $10 \%$ above the original conductance in air after releasing the test gas, respectively.

\section{RESULTS AND DISCUSSION}

The diameters of the as-synthesized $\mathrm{SiO}_{2}$ NPs are estimated to be 25 and $40 \mathrm{~nm}$ from the TEM images (Figures S1A,B). An electrospinning technique was employed to construct mesoporous $\mathrm{WO}_{3}$ NFs from precursor solutions containing $\left(\mathrm{NH}_{4}\right)_{6} \mathrm{H}_{2} \mathrm{~W}_{12} \mathrm{O}_{40} \cdot x \mathrm{H}_{2} \mathrm{O}, \mathrm{PVP}, \mathrm{SiO}_{2} \mathrm{NPs}$, and deionized water, as shown in Scheme 1. The as-spun tungsten species/PVP/SiO $\mathrm{NFs}$ was subjected to calcination at $350^{\circ} \mathrm{C}$ in nitrogen, giving rise to $\mathrm{WO}_{3} /$ carbon $/ \mathrm{SiO}_{2} \mathrm{NF}$ owing to the partial carbonization of the PVP species. The carbonized PVP can provide carbon support inside the frameworks, which can prevent the collapse of the fiber morphology during the crystallization process of $\mathrm{WO}_{3}$. Finally, after further pyrolysis at $500^{\circ} \mathrm{C}$ in air, and selective etching with hydrofluoric acid to remove the supporting carbon species and $\mathrm{SiO}_{2}$ sacrificing templates, mesoporous $\mathrm{WO}_{3} \mathrm{NFs}$ is formed as a result. By using $\mathrm{SiO}_{2}$ NPs with different diameters, two $\mathrm{WO}_{3} \mathrm{NFs}$ can be obtained and denoted as mesoporous $\mathrm{WO}_{3}$ $x$ NFs, wherein $x$ represents the particle size of $\mathrm{SiO}_{2} \mathrm{NPs}$. For comparison, non-mesoporous $\mathrm{WO}_{3} \mathrm{NFs}$ was also synthesized via the same approach but without $\mathrm{SiO}_{2} \mathrm{NPs}$ loading.

Field-emission scanning electron microscopy (FE-SEM) observation reveals that all of the as-spun composites have a uniform fiber-like morphology with a dimeter of about 450$500 \mathrm{~nm}$ (Figure 2A; Figures S2A, S3A) and smooth surfaces (insets in Figure 2A; Figures S2A, S3A). After pyrolysis in $\mathrm{N}_{2}$ at $350^{\circ} \mathrm{C}$, black $\mathrm{WO}_{3} /$ carbon $/ \mathrm{SiO}_{2}(25 \mathrm{~nm}), \mathrm{WO}_{3} /$ carbon $/ \mathrm{SiO}_{2}$ $(40 \mathrm{~nm})$, and $\mathrm{WO}_{3} /$ carbon $\mathrm{NFs}$ can be obtained, owing to the partially carbonization of the PVP species. Compared to the as-spun NFs, the composites retained their uniform fiber morphology, and much rougher surfaces are clearly visible in the surface (Figure 2B; Figures S2B, S3B). After complete removal of carbon and silica species by further calcination in air at $500^{\circ} \mathrm{C}$ and etching with hydrofluoric acid, all the $\mathrm{WO}_{3} \mathrm{NFs}$ also retained the fiber morphology, indicating a good thermal stability, and their diameters were decreased to $250-300 \mathrm{~nm}$ due to the framework shrinkage at high temperature (Figure 2C; Figures S2C, S3C). It is worth noting that the $\mathrm{WO}_{3} \mathrm{NFs}$ consisted of large numbers of nanograins, and boundaries can be clearly observed. An FESEM image taken along the cross-section 

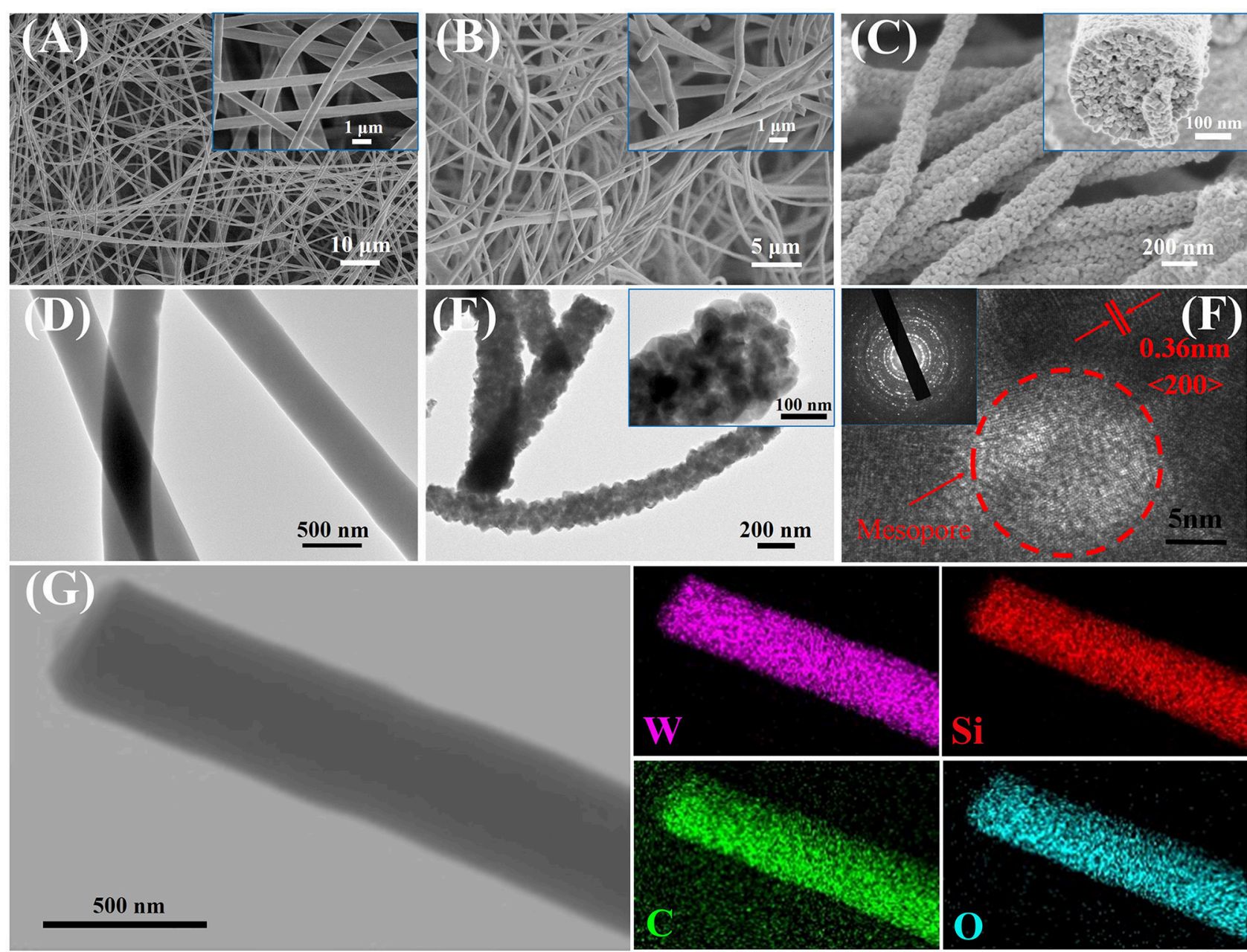

FIGURE 2 | FESEM images of (A) as-spun tungsten species/PVP/SiO 2 (25 nm) NFs, (B) $\mathrm{WO}_{3} /$ carbon/SiO 2 (25 nm) NFs, (C) mesoporous WO $\mathrm{WO}_{3}-25 \mathrm{NFs}$. TEM images of (D) $\mathrm{WO}_{3} /$ carbon $/ \mathrm{SiO}_{2}(25 \mathrm{~nm}) \mathrm{NFs}$, (E) mesoporous $\mathrm{WO}_{3}-25 \mathrm{NFs}$. HRTEM image of (E) mesoporous $\mathrm{WO}_{3}-25 \mathrm{NFs}$. (F) Scanning TEM image and the corresponding EDS mapping images (G) of elemental W, $\mathrm{Si}, \mathrm{C}$, and $\mathrm{O}$ for $\mathrm{WO}_{3} /$ carbon $/ \mathrm{SiO}_{2}(25 \mathrm{~nm}) \mathrm{NFs}$.

of the mesoporous $\mathrm{WO}_{3}-25$ NFs clearly indicates the existence of mesopores around 25-30 nm (inset in Figure 2C), which is in good agreement with the diameter of $\mathrm{SiO}_{2}$ nanoparticles. Due to a larger diameter of the sacrificial $\mathrm{SiO}_{2}$ template, uniform mesopores of about $40-50 \mathrm{~nm}$ can be clearly visible in the SEM image of mesoporous $\mathrm{WO}_{3}-40 \mathrm{NFs}$ (Figure S2C). And no obvious mesopores were observed on non-mesoporous $\mathrm{WO}_{3}$ NFs (Figure S3C), attributing to the absence of the sacrificial $\mathrm{SiO}_{2}$ template.

Transmission electron microscopy (TEM) observations further confirmed that the NFs obtained after pyrolysis at $350^{\circ} \mathrm{C}$ are fibrous in shape with a diameter of $400-450 \mathrm{~nm}$ (Figure 2D; Figures S2D, S3D). The scanning TEM (STEM) image and energy dispersive $\mathrm{X}$-ray elemental mapping recorded on $\mathrm{WO}_{3} /$ carbon $/ \mathrm{SiO}_{2}(25 \mathrm{~nm}) \mathrm{NFs}$ clearly reveals that the $\mathrm{W}$, $\mathrm{Si}, \mathrm{C}$, and $\mathrm{O}$ elements are homogeneously distributed in entire NFs (Figure 2G). It suggests that the carbonized PVP molecules can provide rigid support inside the frameworks, forming a "reinforced-concrete" framework structure with $\mathrm{WO}_{3}$ species. which can prevent the collapse of the NFs. TEM images of mesoporous $\mathrm{WO}_{3}-25$ and mesoporous $\mathrm{WO}_{3}-40$ NFs clearly indicate that the fiber-like morphology are well-retained, and the material consists of interconnected $\mathrm{WO}_{3}$ nanoparticles, as well as the existence of numerous mesopores (Figure 2E; Figure S2E), which can offer abundant active sites to interact with guest molecules, greatly facilitating the diffusion of gas molecules. Additional EDS analyses of the mesoporous $\mathrm{WO}_{3}-25 \mathrm{NFs}$ and $\mathrm{WO}_{3}-40 \mathrm{NFs}$ were carried out as depicted in Figures $\mathbf{S 4 A , B}$, respectively. The absence of peaks from $\mathrm{Si}$ in the EDS spectrum indicates the complete removal of $\mathrm{SiO}_{2}$ by $\mathrm{HF}$ etching. Similarly, no obvious mesopores, but only $\mathrm{WO}_{3}$ nanoparticles, were shown in the TEM image of non-mesoporous $\mathrm{WO}_{3}$ NFs (Figure S3E). High resolution TEM (HR-TEM) images of mesoporous and non-mesoporous $\mathrm{WO}_{3}$ NFs clearly show the lattice fringes of tungsten oxide with a $d$ spacing of $0.36 \mathrm{~nm}$ (Figure 2F; Figures S2F, S3F), corresponding 

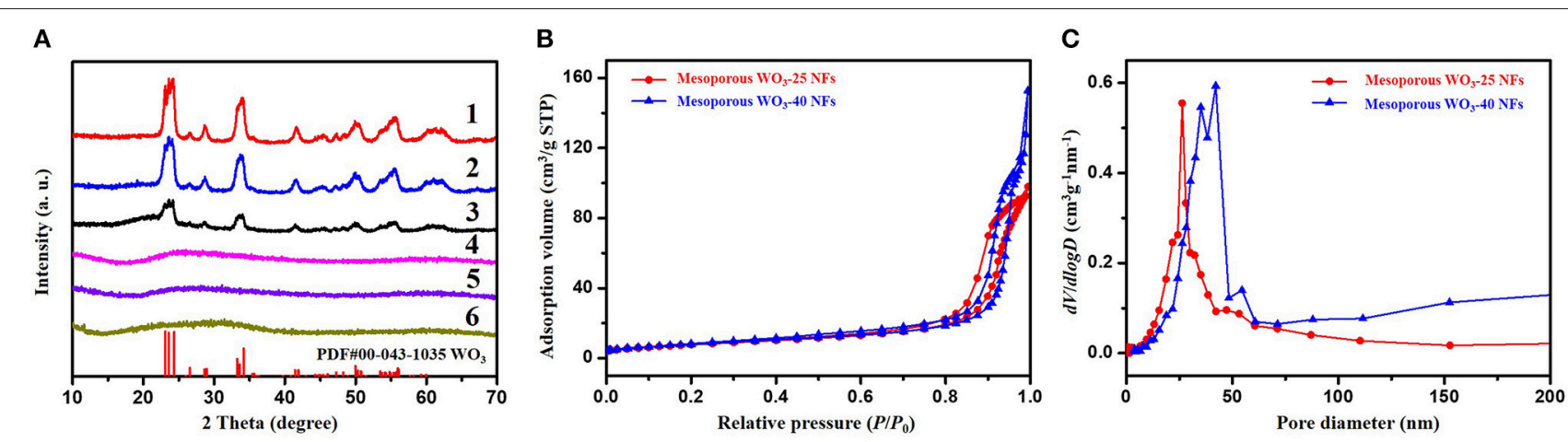

FIGURE 3 | (A) XRD patterns of (1) mesoporous $\mathrm{WO}_{3}-25 \mathrm{NFs}$, (2) mesoporous $\mathrm{WO}_{3}-40 \mathrm{NFs}$, (3) non-mesoporous $\mathrm{WO}_{3} \mathrm{NFs}$, (4) $\mathrm{WO}_{3} / \mathrm{carbon} \mathrm{SiO}_{2}$ (25 $\mathrm{nm}_{\text {) }} \mathrm{NFs}$, (5) $\mathrm{WO}_{3} /$ carbon/ $\mathrm{SiO}_{2}(40 \mathrm{~nm}) \mathrm{NFs},(6) \mathrm{WO}_{3} /$ carbon NFs. (B) Nitrogen-sorption isotherms and (C) pore size distribution curves of mesoporous $\mathrm{WO}_{3}-25 \mathrm{NFs}$ and mesoporous $\mathrm{WO}_{3}-40 \mathrm{NFs}$.

to the (200) planes, suggesting that the framework consists of well-crystallized and interconnected $\mathrm{WO}_{3}$ nanoparticles. Selected-area electron diffraction (SAED), recorded on different $\mathrm{WO}_{3}$ NFs showed well-resolved diffraction rings corresponding with the (200), (112), and (022) crystal planes of monoclinic phase $\mathrm{WO}_{3}$ (insets in Figure 2F, Figures S2F, S3F), further confirming the crystalline feature of the scaffold.

Wide-angle X-ray diffraction (WA-XRD) patterns indicate that the $\mathrm{WO}_{3} /$ carbon $/ \mathrm{SiO}_{2}(25 \mathrm{~nm}), \mathrm{WO}_{3} /$ carbon $/ \mathrm{SiO}_{2}(40 \mathrm{~nm})$, and $\mathrm{WO}_{3} /$ carbon NFs exbibits the amorphous feature contributing to the poor crystallization (Figure 3A). After crystallization at $500^{\circ} \mathrm{C}$, and removal of the silica nanoparticles by selective etching with hydrofluoric acid, mesoporous $\mathrm{WO}_{3}$ 25 , mesoporous $\mathrm{WO}_{3}-40$ and non-mesoporous $\mathrm{WO}_{3} \mathrm{NFs}$ shows well-resolved diffraction peaks in the range of $10-70^{\circ} \mathrm{C}$, matching well with the crystalline monoclinic phase of $\mathrm{WO}_{3}$ with lattice parameters of $\mathrm{a}=0.7297, \mathrm{~b}=0.7539, \mathrm{c}=0.7688 \mathrm{~nm}$, and $\beta=90.91$ (JCPDS No. 43-1,035). No diffraction peaks from other crystalline impurities are observed in the XRD patterns, indicating pure crystalline phase, which agreeing well with the HR-TEM results. The broadening of the diffraction peaks can be attributed to the small particle size of $\mathrm{WO}_{3}$ nanocrystals (Li et al., 2014).

Nitrogen adsorption-desorption isotherms of the obtained mesoporous $\mathrm{WO}_{3}-25$ NFs exhibit type-IV curves with $\mathrm{H} 1$ hysteresis loop (Figure 3B). The steep increase in the adsorption band at $P / P_{0}=0.75-0.96$ indicates mesopores with a large and uniform pore size. The pore diameter is about $26.3 \mathrm{~nm}$ as indicated in the pore size distributions derived from the adsorption branch of the isotherms by using Barrett-JoynerHalenda (BJH) model (Figure 3C). The specific surface area and total pore volume of mesoporous $\mathrm{WO}_{3}-25 \mathrm{NFs}$ are calculated to be as high as $34.4 \mathrm{~m}^{2} \mathrm{~g}^{-1}$ and $0.15 \mathrm{~cm}^{3} \mathrm{~g}^{-1}$, respectively. Similarly, mesoporous $\mathrm{WO}_{3}-40$ NFs also display type-IV curves with sharp capillary condensation steps in the relative pressure range of $0.78-0.97$ (Figure $3 B$ ). The pore size distribution profile reveals a mesopore size of $42.2 \mathrm{~nm}$ (Figure 3C), indicating that the hard template silica nanoparticles with larger diameters result in larger mesopores. The surface area and total pore volume of mesoporous $\mathrm{WO}_{3}-40$ NFs are approximately 24.1 $\mathrm{m}^{2} \mathrm{~g}^{-1}$ and $0.24 \mathrm{~cm}^{3} \mathrm{~g}^{-1}$, respectively. Such a porous structure provides an amplified target-receptor interface and is beneficial for the diffusion and adsorption of large guest molecules, making it an ideal candidate for many applications involving host-guest interactions, such as catalysis and gas sensing. In addition, nitrogen adsorption-desorption isotherms of nonmesoporous $\mathrm{WO}_{3}$-NFs show type-IV curves with $\mathrm{H} 3$ hysteresis loop (Figure S5A). The surface area and total pore volume of non-mesoporous $\mathrm{WO}_{3} \mathrm{NFs}$ is $19.5 \mathrm{~m}^{2} \mathrm{~g}^{-1}$ and $0.17 \mathrm{~cm}^{3} \mathrm{~g}^{-1}$, respectively. The average pore size calculated from the adsorption branch using the $\mathrm{BJH}$ method is about $5.3 \mathrm{~nm}$ (Figure S5B), much smaller than that of the etched samples $(26.3 \mathrm{~nm}$ for mesoporous $\mathrm{WO}_{3}-25 \mathrm{NFs}$ and $42.2 \mathrm{~nm}$ for mesoporous $\mathrm{WO}_{3}$ $40 \mathrm{NFs}$ ), which can be attributed to the stacked pores of small $\mathrm{WO}_{3}$ grains.

$\mathrm{X}$-ray photoelectron spectroscopy (XPS) is further used to investigate the surface composition and elemental states of the NFs before and after etching. For the $\mathrm{WO}_{3} / \mathrm{SiO}_{2}(25 \mathrm{~nm})$ composite NFs (denoted as $\mathrm{WO}_{3}-25 / \mathrm{SiO}_{2} \mathrm{NFs}$ ) before etching, four peaks corresponding to $\mathrm{W} 4 \mathrm{f}, \mathrm{Si} 2 \mathrm{p}, \mathrm{W} 4 \mathrm{~d}$ and $\mathrm{O} 1 \mathrm{~s}$ are shown in the survey spectrum (Figure S6A). However, after etching, the Si $2 \mathrm{p}$ peak at $103.3 \mathrm{eV}$ disappears, indicating the complete removal of $\mathrm{SiO}_{2}$ species by $\mathrm{HF}$ (Xu et al., 2015; Shi et al., 2016). The high-resolution XPS W 4d spectrum (Figure S6B) of the samples after etching show similar spectra and can be fitted with two peaks centering at 35.8 and $37.9 \mathrm{eV}$, which can be assigned to $\mathrm{W}^{6+} 4 \mathrm{f}_{7 / 2}$ and $\mathrm{W}^{6+} 4 \mathrm{f}_{5 / 2}$, respectively (Wang et al., 2012). These results indicate that completely oxidized $W$ is not changed during the etching process in mesoporous $\mathrm{WO}_{3}-25$ NFs, mesoporous $\mathrm{WO}_{3}-40 \mathrm{NFs}$ and non-mesoporous $\mathrm{WO}_{3} \mathrm{NFs}$ samples. The state of $\mathrm{O} 1 \mathrm{~s}$ indicates two types of oxygen in the surface (Figure S6C), lattice oxygen $\left(\mathrm{O}^{2-}\right)$ and adsorbed oxygen $\left(\mathrm{O}^{-}\right.$and $\left.\mathrm{O}^{2-}\right)$. Usually, the adsorbed oxygen was more active to react with reducing gases compared with lattice oxygen, changing the concentration of main carriers (Zhu et al., 2017a).

Inspired by the unique structure of obtained mesoporous $\mathrm{WO}_{3}$ fibers with ultra-large and controllable pore size, we tested the performance of mesoporous $\mathrm{WO}_{3}-25$, mesoporous $\mathrm{WO}_{3}-40$ 
A
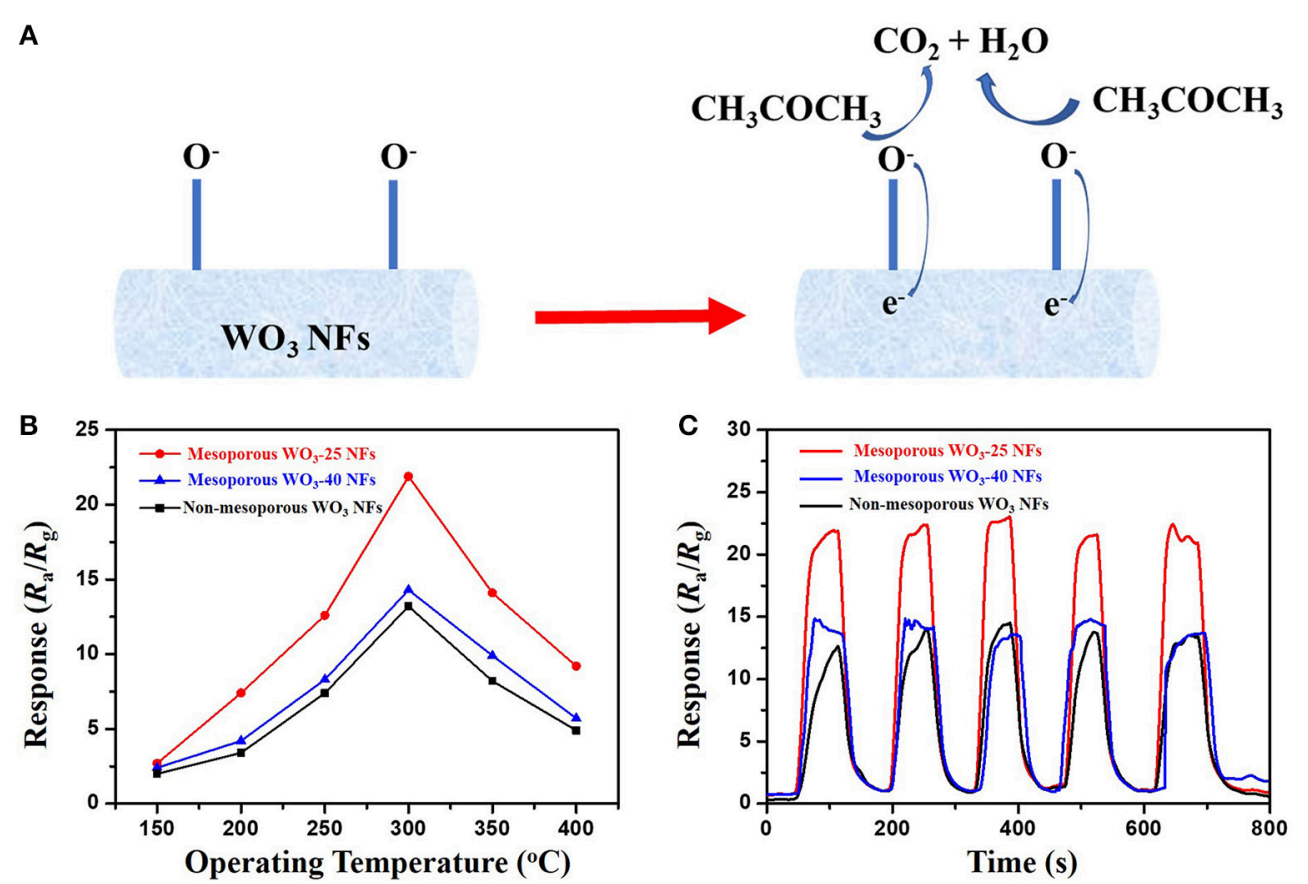

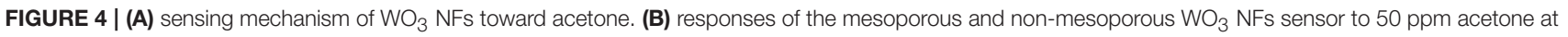
different operating temperatures $\left(150-400^{\circ} \mathrm{C}\right)$. (C) repeating response and recovery curve of the mesoporous and non-mesoporous $\mathrm{WO}_{3} \mathrm{NFs}$ to 50 ppm acetone.

and non-mesoporous $\mathrm{WO}_{3} \mathrm{NFs}$ as sensing materials for the detection of acetone to investigate their potential application in the detection of acetone leakage and diagnosis for diabetes. The schematic diagram of sensing mechanism is shown in Figure 4A. In the gas sensing test, probe gases such as acetone were injected into a test chamber and mixed with air. The gas response of the sensor in this study is defined as $S=R_{\mathrm{a}} / R_{\mathrm{g}}$, where $R_{\mathrm{a}}$ and $R_{\mathrm{g}}$ is the resistance of the sensor in air and test gas, respectively. The response time is defined as the time required from $R_{\mathrm{a}}$ to $R_{\mathrm{a}}-90 \% \times\left(R_{\mathrm{a}}-R_{\mathrm{g}}\right)$ after a test gas was injected, and the recovery time is defined as the time required from $R_{\mathrm{g}}$ to $R_{\mathrm{g}}+$ $90 \% \times\left(R_{\mathrm{a}}-R_{\mathrm{g}}\right)$ in air after releasing the test gas, respectively. Since the sensing performances of semiconductors for a specific gas are usually dependent on the working temperature, parallel tests of mesoporous $\mathrm{WO}_{3}-25$, mesoporous $\mathrm{WO}_{3}-40$ and nonmesoporous $\mathrm{WO}_{3}$ NFs based sensors were carried out toward a $50 \mathrm{ppm}$ acetone gas in a range of $150-400^{\circ} \mathrm{C}$ to optimize the working temperature region (Figure $4 \mathrm{~B}$ ). It can be seen that the response of all sensors increased continuously until reaching a maximum value at $300^{\circ} \mathrm{C}$ and then decreased upon increase of the operating temperature. Such response behavior is due to the balance of the competition between the increase of the surface reaction rates and the decrease in the number of active sites for the adsorption of acetone at high temperatures. As a result, $300^{\circ} \mathrm{C}$ was adopted as the optimum working temperature for subsequent acetone detections.

In contrast, it was found that both of the mesoporous sensing materials, mesoporous $\mathrm{WO}_{3}-25$ and $\mathrm{WO}_{3}-40$ NFs, have shown higher responses to acetone than the non-mesoporous $\mathrm{WO}_{3} \mathrm{NFs}$.
Such phenomenon may contribute to the uniform mesopores and interconnected transportation channels of mesoporous $\mathrm{WO}_{3}$ NFs resulting from the sacrificial templates including silica nanoparticles and PVP species, which provides a huge interface for the creation of active sites for acetone gas interaction, and greatly facilitates the diffusion of gas molecules in the framework. In addition, the response value increases dramatically from 13.7 for mesoporous $\mathrm{WO}_{3}-40 \mathrm{NF}$ to 22.1 for mesoporous $\mathrm{WO}_{3}-25$ NFs at the same temperature, indicating that the sensitivity of the materials is closely related to its specific surface area. Mesoporous $\mathrm{WO}_{3}-25 \mathrm{NFs}$ with a higher surface area $\left(34.4 \mathrm{~m}^{2} \mathrm{~g}^{-1}\right)$ could provide more active surface sites for numerous surface reactions between guest molecules and adsorbed oxygen species on the solid-gas interface. Therefore, the response value of mesoporous $\mathrm{WO}_{3}-25 \mathrm{NFs}$ is higher than the non-mesoporous $\mathrm{WO}_{3} \mathrm{NFs}$ during the operating temperature range from 150 to $400^{\circ} \mathrm{C}$ (Figure 4B), and the sensitivity of mesoporous $\mathrm{WO}_{3}-25 \mathrm{NFs}$ is $66 \%$ higher than that of non-mesoporous $\mathrm{WO}_{3}$ for $50 \mathrm{ppm}$ at the optimal operation temperature (Figure 4C). Moreover, the mesoporous $\mathrm{WO}_{3}-25 \mathrm{NFs}$ shows a response time of $24 \mathrm{~s}$, much shorter than that of non-mesoporous $\mathrm{WO}_{3}(67 \mathrm{~s})$, as shown in the Figure S7. The faster response is mainly attributed to its porous structure, which could facilitate the diffusion and transport of target gas via enormous pore channels to interact with $\mathrm{WO}_{3} \mathrm{NFs}$, quickly reaching the maximum sensitivity. The reversible cycles of the response curves illustrate a stable and reliable operation of acetone sensing of all the $\mathrm{WO}_{3} \mathrm{NFs}$, and further confirm the consistency of mesoporous $\mathrm{WO}_{3}$ 25 NFs based sensors (Figure 4C). The continuous dynamic 

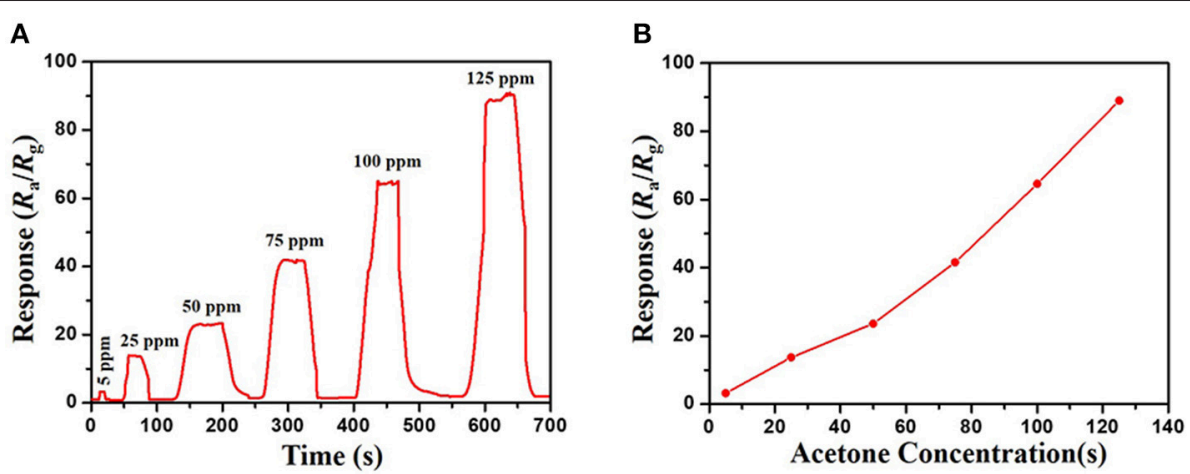

C

D
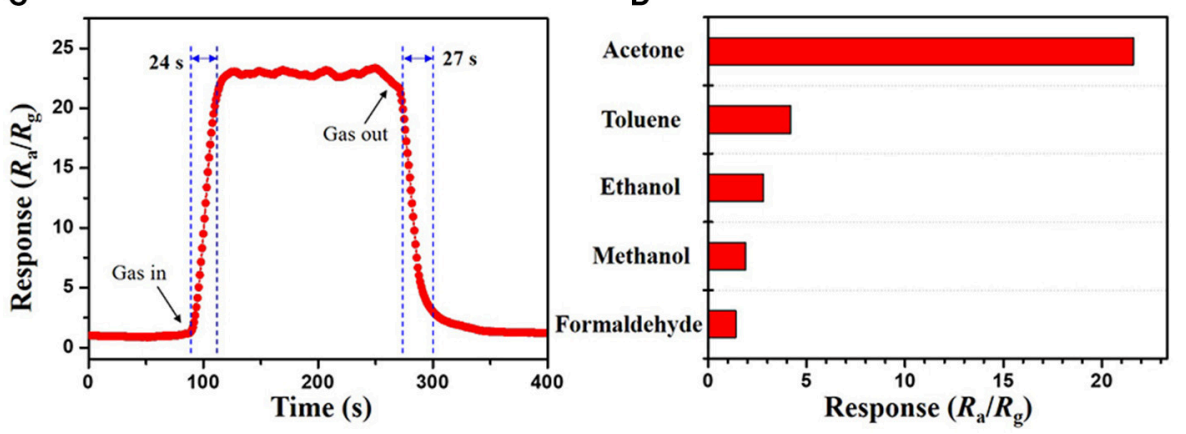

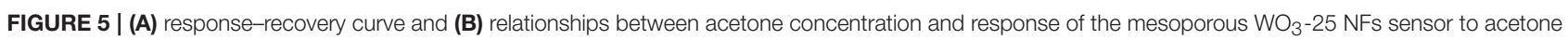
vapors of different concentrations. (C) dynamic response-recovery curve of mesoporous $\mathrm{WO}_{3}-25 \mathrm{NFs}$ sensor to 50 ppm acetone. (D) responses of the mesoporous $\mathrm{WO}_{3}-25 \mathrm{NFs}$ sensor to various gases at $50 \mathrm{ppm}$.

electrical response of mesoporous $\mathrm{WO}_{3}-25 \mathrm{NFs}$ toward different concentration of acetone (5-125 ppm) at $300^{\circ} \mathrm{C}$ is shown in Figure 5A. With the increase in acetone concentration, the response values of mesoporous $\mathrm{WO}_{3}-25 \mathrm{NFs}$ based gas sensors rapidly increased from 3.1 at $5 \mathrm{ppm}$ to 89 at $125 \mathrm{ppm}$. After aeration, the acetone molecules desorbed immediately from the surface of tungsten oxides. The response can be recovered to its initial value for all the testing concentrations, reflecting a good reversibility of the gas sensor. Surprisingly, the minimum detectable concentration can reach as low as 1 ppm (Figure S8). As shown in Figure 5B, a linear relationship between the sensing response and acetone concentrations is observed, indicating the feasibility of quantitative acetone detection by the mesoporous $\mathrm{WO}_{3} \mathrm{NFs}$ based sensors. As important parameters for a gas sensor, the response and recovery behaviors are also crucial for evaluating the sensing performance. The mesoporous $\mathrm{WO}_{3}$ 25 NFs based sensor exhibits a fast response of $24 \mathrm{~s}$ upon exposure to $50 \mathrm{ppm}$ acetone and quick recovery of $27 \mathrm{~s}$ when acetone gas was removed (Figure 5C). In addition, compared with earlier reported acetone sensors, our mesoporous $\mathrm{WO}_{3} \mathrm{NFs}$ exhibits much better comprehensive sensing performance such as high sensitivity, low limits of detection and fast responserecovery (Table $\mathbf{1}$ ), thus becoming a promising candidate for acetone sensing in environmental monitoring and rapid medical diagnosis. Based on the aforementioned results, the predominant enhancement could mainly be explained as follows: (1) The unique hierarchical structure where uniform and controllable mesopores are well-connected with enormous transportation channels derived from PVP species, which facilitate the rapid diffusion of gas molecules. (2) The high specific surface area with abundant active sites enables the adsorption of a large amount of acetone molecules. (3) The continuous crystalline framework is also favorable for the fast transportation of charge carriers from the surface into bulk. It can therefore be concluded that the unique feature of our materials can maximize the performance of gas sensing. The selectivity of gas sensors is also an important parameter in practical applications. In this work, four kinds of typical vaporous molecules with identical concentration of 50 ppm, such as methanol, ethanol, toluene, and formaldehyde were selected as interfering gases. As illustrated in Figure 5D, the response value of a mesoporous $\mathrm{WO}_{3}-25 \mathrm{NFs}$ based sensor to acetone was at least four times higher than that of interfering gases, which implies an excellent selectivity.

In summary, mesoporous $\mathrm{WO}_{3}$ NFs with controllable pore diameters were synthesized via a facile electrospinning of an aqueous solution containing ammonium paratungstate, PVP and $\mathrm{SiO}_{2}$ NPs sacrificing templates, followed by controlled pyrolysis at a high temperature and selective etching with hydrofluoric acid. The PVP species can provide rigid support inside frameworks, which can prevent the collapse of the unique fiber morphology and the well-connected porous structure. The decomposition of the PVP species during calcination and the etching of $\mathrm{SiO}_{2} \mathrm{NPs}$ was also found to contribute to the formation of interconnected transportation channels and 
TABLE 1 | Comparison of acetone sensing properties of $\mathrm{WO}_{3}$ or $\mathrm{WO}_{3}$ based sensors with various nanostructures.

\begin{tabular}{|c|c|c|c|c|c|}
\hline Structures & Working temperature & $\begin{array}{l}\text { Acetone concentration } \\
\text { (ppm) }\end{array}$ & $\begin{array}{c}\text { Response } \\
\left(R_{\mathrm{a}} / R_{\mathrm{g}}\right)\end{array}$ & $\begin{array}{c}\text { Response/recovery } \\
\text { time }\end{array}$ & References \\
\hline Porous $\mathrm{WO}_{3}$ & $300^{\circ} \mathrm{C}$ & 50 & 12.1 & $4 / 11.7 \mathrm{~s}$ & Dong et al., 2016 \\
\hline $\mathrm{WO}_{3}$ plate & $307^{\circ} \mathrm{C}$ & 100 & $\sim 15$ & $10 / 26 s$ & Liu et al., 2012 \\
\hline $\mathrm{WO}_{3}$ nanoflowers & $300^{\circ} \mathrm{C}$ & 100 & $\sim 7$ & Not mentioned & Wang et al., 2013 \\
\hline $\mathrm{Co}_{3} \mathrm{O}_{4}-\mathrm{WO}_{3}$ nanocomposite & $280^{\circ} \mathrm{C}$ & 100 & 5.3 & Not mentioned & Zhao et al., 2015 \\
\hline Ag-WO3 nanosheets & $340^{\circ} \mathrm{C}$ & 50 & $\sim 8$ & $28 / 38 s$ & Yin et al., 2017 \\
\hline $\mathrm{MoO}_{3}-\mathrm{WO}_{3}$ nanostructures & $320^{\circ} \mathrm{C}$ & 100 & 18.2 & $8 / 7 s$ & Sun et al., 2017 \\
\hline WO $@$ @ $\mathrm{CuO}$ nanostructures & Not mentioned & 50 & 3.4 & $72.2 / 29.4 s$ & Yang F. et al., 2018 \\
\hline cactus-like $\mathrm{WO}_{3}-\mathrm{SnO}_{2}$ & $360^{\circ} \mathrm{C}$ & 100 & 12.1 & Not mentioned & Zhu et al., 2018 \\
\hline $\begin{array}{l}\text { Gd doped } \mathrm{WO}_{3}-\mathrm{RGO} \\
\text { nanostructures }\end{array}$ & $350^{\circ} \mathrm{C}$ & 50 & 27.0 & Not mentioned & Kaur et al., 2018 \\
\hline $\mathrm{La}_{2} \mathrm{O}_{3}-\mathrm{WO}_{3}$ nanofibers & $350^{\circ} \mathrm{C}$ & 100 & 12.7 & $6 / 210 s$ & Feng et al., 2015 \\
\hline Mesoporous $\mathrm{WO}_{3} \mathrm{NFs}$ & $350^{\circ} \mathrm{C}$ & 50 & 22.1 & $24 / 27 s$ & This wok \\
\hline
\end{tabular}

uniform mesopores in the framework of the fibers. The obtained mesoporous $\mathrm{WO}_{3}$ NFs possess a tunable pore size (26.3 and $42.2 \mathrm{~nm}$ ), high surface area and pore volume (up to $34.4 \mathrm{~m}^{2} / \mathrm{g}$ and $0.24 \mathrm{~cm}^{3} \mathrm{~g}^{-1}$ ), and a well-developed hierarchical porous structure and crystalline pore walls. Sensors based on these materials were found to have an excellent acetone sensing performance with a fast response (24s) and recovery (27s), a low detection limit of $1 \mathrm{ppm}$, excellent selectivity and good stability, due to their high mesoporosity, abundant active sites and the continuous crystalline framework. Based on the above-mentioned results, the obtained mesoporous $\mathrm{WO}_{3}$ NFs holds great promise for applications in various fields such as portable miniaturized devices used for environmental monitoring, and breath analysis used for disease pre-diagnosis and home security. Moreover, it is expected that the facile and effective electrospinning approach may open up new opportunities for the design of various mesoporous metal oxide NFs with high surface areas, crystalline frameworks and greatly improved mass diffusion and transportation for application in sensors, catalysis, energy storage and conversion.

\section{AUTHOR CONTRIBUTIONS}

WL and JY conceived and designed the experiments. HX, TZ, YZ and JG performed the experiments. ML, GZ, LW, WJ, YF,

\section{REFERENCES}

Barr, T. J., Sampaio, R. N., Dimarco, B. N., James, E. M., and Meyer, G. J. (2017). Phantom electrons in mesoporous nanocrystalline $\mathrm{SnO}_{2}$ thin films with cation-dependent reduction onsets. Chem. Mater. 29, 3919-3927. doi: 10.1021/acs.chemmater.6b05470

Barsan, N., and Weimar, U. (2001). Conduction model of metal oxide gas sensors. J. Electroceram. 7, 143-167. doi: 10.1023/A:1014405811371

Channei, D., Nakaruk, A., Khanitchaidecha, W., Jannoey, P., and Phanichphant, S. (2018). Adsorption and photocatalytic processes of mesoporous $\mathrm{SiO}_{2}$ coated monoclinic $\mathrm{BiVO}_{4}$. Front. Chem. 6:415. doi: 10.3389/fchem.2018. 00415
MZ analyzed the data. WL and HX wrote the manuscript. XQ designed the scheme. All authors reviewed the manuscript and approved the final version.

\section{FUNDING}

This work was supported by National Natural Science Foundation of China (51822202, 51772050, 51702046, 51432004, 51774096), the Shanghai Rising-Star Program (18QA1400100), the Shanghai Committee of Science and Technology, China (No. 17ZR1401000), the Shanghai Pujiang Program (No. 17PJ1400100), the Youth Top-notch Talent Support Program of Shanghai, the Program for Professor of Special Appointment (Eastern Scholar) at Shanghai Institutions of Higher Learning, the DHU Distinguished Young Professor Program and the Fundamental Research Funds for the Central Universities, the Innovation Program of Shanghai Municipal Education Commission (2017-01-07-00-03-E00025).

\section{SUPPLEMENTARY MATERIAL}

The Supplementary Material for this article can be found online at: https://www.frontiersin.org/articles/10.3389/fchem. 2019.00266/full\#supplementary-material 
sensing. Mater. Chem. Phys. 184, 155-161. doi: 10.1016/j.matchemphys. 2016.09.036

Du, J., Lai, X., Yang, N., Zhai, J., Kisailus, D., Su, F., et al. (2011). Hierarchically ordered macro-mesoporous $\mathrm{TiO}_{2}$-graphene composite films: improved mass transfer, reduced charge recombination, and their enhanced photocatalytic activities. ACS Nano 5, 590-596. doi: 10.1021/ nn102767d

Feng, C., Wang, C., Cheng, P., Li, X., Wang, B., Guan, Y., et al. (2015). Facile synthesis and gas sensing properties of $\mathrm{La}_{2} \mathrm{O}_{3}-\mathrm{WO}_{3}$ nanofibers. Sensors Actuators B Chem. 221, 434-442. doi: 10.1016/j.snb.2015.06.114

Guo, P., Zhao, G., Chen, P., Lei, B., Jiang, L., Zhang, H., et al. (2014). Porphyrin nanoassemblies via surfactant-assisted assembly and single nanofiber nanoelectronic sensors for high-performance $\mathrm{H}_{2} \mathrm{O}_{2}$ vapor sensing. ACS Nano 8, 3402-3411. doi: 10.1021/nn406071f

He, B., Wang, J., Fan, Y., Jiang, Y., Zhai, Y., Wang, Y., et al. (2018). Mesoporous $\mathrm{CoO} / \mathrm{Co}-\mathrm{N}-\mathrm{C}$ nanofibers as efficient cathode catalysts for $\mathrm{Li}-\mathrm{O}_{2}$ batteries. $J$. Mater. Chem. A 6, 19075-19084. doi: 10.1039/C8TA07185C

Jeong, Y. J., Koo, W. T., Jang, J. S., Kim, D. H., Cho, H. J., and Kim, I. D. (2018). Chitosan-templated Pt nanocatalyst loaded mesoporous $\mathrm{SnO}_{2}$ nanofibers: a superior chemiresistor toward acetone molecules. Nanoscale 10, 13713-13721. doi: $10.1039 / C 8 N R 03242 D$

Jha, G., Tran, T., Qiao, S., Ziegler, J. M., Ogata, A. F., Dai, S., et al. (2018). Electrophoretic deposition of mesoporous Niobium(V)oxide nanoscopic films. Chem. Mater. 30, 6549-6558. doi: 10.1021/acs.chemmater. $8 \mathrm{~b} 03254$

Jha, R. K., Wan, M., Jacob, C., and Guha, P. K. (2018). Ammonia vapour sensing properties of in situ polymerized conducting PANI-nanofiber/WS 2 nanosheet composites. N. J. Chem. 42, 735-745. doi: 10.1039/C7NJ03343E

Jia, Q., Ji, H., Zhang, Y., Chen, Y., Sun, X., and Jin, Z. (2014). Rapid and selective detection of acetone using hierarchical $\mathrm{ZnO}$ gas sensor for hazardous odor markers application. J. Hazar. Mater. 276, 262-270. doi: 10.1016/.j. hazmat.2014.05.044

Kaneti, Y. V., Salunkhe, R. R., Wulan Septiani, N. L., Young, C., Jiang, X., He, Y. B., et al. (2018). General template-free strategy for fabricating mesoporous twodimensional mixed oxide nanosheets via self-deconstruction/reconstruction of monodispersed metal glycerate nanospheres. J. Mater. Chem. A 6, 5971-5983. doi: $10.1039 / \mathrm{C} 8 \mathrm{TA} 00008 \mathrm{E}$

Kaur, J., Anand, K., Kaur, A., and Singh, R. C. (2018). Sensitive and selective acetone sensor based on $\mathrm{Gd}$ doped $\mathrm{WO}_{3} /$ reduced graphene oxide nanocomposite. Sensors Actuators B Chem. 258, 1022-1035. doi: 10.1016/j.snb.2017.11.159

Kawano, T., Chiamori, H. C., Suter, M., Zhou, Q., Sosnowchik, B. D., and Lin, L. (2007). An electrothermal carbon nanotube gas sensor. Nano Lett. 7 , 3686-3690. doi: $10.1021 / \mathrm{nl} 071964 \mathrm{~s}$

Kim, H. J., and Lee, J. H. (2014). Highly sensitive and selective gas sensors using ptype oxide semiconductors: overview. Sensors Actuators B Chem. 192, 607-627. doi: 10.1016/j.snb.2013.11.005

Kim, S. J., Choi, S. J., Jang, J. S., Kim, N. H., Hakim, M., Tuller, H. L., et al. (2016a). Mesoporous $\mathrm{WO}_{3}$ nanofibers with protein-templated nanoscale catalysts for detection of trace biomarkers in exhaled breath. ACS Nano 10, 5891-5899. doi: 10.1021/acsnano.6b01196

Li, F., Chen, L., Knowles, G. P., Macfarlane, D. R., and Zhang, J. (2017). Hierarchical mesoporous $\mathrm{SnO}_{2}$ nanosheets on carbon cloth: a robust and flexible electrocatalyst for $\mathrm{CO}_{2}$ reduction with high efficiency and selectivity. Angewandte Chem Int. Edn. 56, 505-509. doi: 10.1002/anie.201608279

Li, X., Ding, K., Gao, B., Li, Q., Li, Y., Fu, J., et al. (2017). Freestanding carbon encapsulated mesoporous vanadium nitride nanowires enable highly stable sulfur cathodes for lithium-sulfur batteries. Nano Energy 40, 655-662. doi: 10.1016/j.nanoen.2017.09.018

Li, Y., Luo, W., Qin, N., Dong, J., Wei, J., Li, W., et al. (2014). Highly ordered mesoporous tungsten oxides with a large pore size and crystalline framework for $\mathrm{H}_{2} \mathrm{~S}$ sensing. Angewandte Chem. Int. Edn. 53, 9035-9040. doi: $10.1002 /$ anie. 201403817

Liu, S., Zhang, F., Li, H., Chen, T., and Wang, Y. (2012). Acetone detection properties of single crystalline tungsten oxide plates synthesized by hydrothermal method using cetyltrimethyl ammonium bromide supermolecular template. Sensors Actuators B Chem. 162, 259-268. doi: 10.1016/j.snb.2011.12.076
Luo, W., Li, Y., Dong, J., Wei, J., Xu, J., Deng, Y., et al. (2013). A resolassisted co-assembly approach to crystalline mesoporous niobia spheres for electrochemical biosensing. Angewandte Chem. Int. Edn. 52, 10505-10510. doi: $10.1002 /$ anie. 201303353

Luo, W., Wang, Y., Wang, L., Jiang, W., Chou, S. L., Dou, S. X., et al. (2016a). Silicon/mesoporous carbon/crystalline $\mathrm{TiO}_{2}$ nanoparticles for highly stable lithium storage. ACS Nano 10, 10524-10532. doi: 10.1021/ acsnano.6b06517

Luo, W., Zhao, T., Li, Y., Wei, J., Xu, P., Li, X., et al. (2016b). A Micelle fusion-aggregation assembly approach to mesoporous carbon materials with rich active sites for ultrasensitive ammonia sensing. J. Am. Chem. Soc. 138, 12586-12595. doi: 10.1021/jacs.6b07355

Ma, J., Ren, Y., Zhou, X., Liu, L., Zhu, Y., Cheng, X., et al. (2018). Pt Nanoparticles sensitized ordered mesoporous $\mathrm{WO}_{3}$ semiconductor: gas sensing performance and mechanism study. Adv. Funct. Mater. 28:1705268. doi: $10.1002 / \mathrm{adfm} .201705268$

Nada, A. A., Nasr, M., Viter, R., Miele, P., Roualdes, S., and Bechelany, M. (2017). Mesoporous $\mathrm{ZnFe}_{2} \mathrm{O}_{4} @ \mathrm{TiO}_{2}$ nanofibers prepared by electrospinning coupled to PECVD as highly performing photocatalytic materials. J. Phys. Chem. C 121, 24669-24677. doi: 10.1021/acs.jpcc.7b08567

Qiu, Z., Hua, Z., Li, Y., Wang, M., Huang, D., Tian, C., et al. (2018). Acetone sensing properties and mechanism of Rh-Loaded $\mathrm{WO}_{3}$ nanosheets. Front Chem. 6, 385-385. doi: 10.3389/fchem.2018.00385

Rakhi, R. B., Chen, W., Cha, D., and Alshareef, H. N. (2012). Substrate dependent self-organization of mesoporous cobalt oxide nanowires with remarkable pseudocapacitance. Nano Lett. 12, 2559-2567. doi: 10.1021/nl300779a

Ren, X., Hou, H., Liu, Z., Gao, F., Zheng, J., Wang, L., et al. (2016). Shape-enhanced photocatalytic activities of thoroughly mesoporous $\mathrm{ZnO}$ nanofibers. Small 12, 4007-4017. doi: 10.1002/smll.201600991

Saha, J., and De, G. (2013). Highly ordered cubic mesoporous electrospun $\mathrm{SiO}_{2}$ nanofibers. Chem. Commun. 49, 6322-6324. doi: 10.1039/c3cc42338g

Salehi, S., Nikan, E., Khodadadi, A. A., and Mortazavi, Y. (2014). Highly sensitive carbon nanotubes- $\mathrm{SnO}_{2}$ nanocomposite sensor for acetone detection in diabetes mellitus breath. Sensors Actuators B Chem. 205, 261-267. doi: 10.1016/j.snb.2014.08.082

Shi, L., Wang, W., Wang, A., Yuan, K., Jin, Z., and Yang, Y. (2016). Scalable synthesis of core-shell structured $\mathrm{SiO}_{\mathrm{x}} /$ nitrogen-doped carbon composite as a high-performance anode material for lithium-ion batteries. J. Power Sources 318, 184-191. doi: 10.1016/j.jpowsour.2016.03.111

Singkammo, S., Wisitsoraat, A., Sriprachuabwong, C., Tuantranont, A., Phanichphant, S., and Liewhiran, C. (2015). Electrolytically exfoliated graphene-loaded flame-made Ni-doped $\mathrm{SnO}_{2}$ composite film for acetone sensing. ACS Appl. Mater. Interfaces 7, 3077-3092. doi: 10.1021/acsami.5b00161

Sun, Y., Chen, L., Wang, Y., Zhao, Z., Li, P., Zhang, W., et al. (2017). Synthesis of $\mathrm{MoO}_{3} / \mathrm{WO}_{3}$ composite nanostructures for highly sensitive ethanol and acetone detection. J. Mater. Sci. 52, 1561-1572. doi: 10.1007/s10853-016-0450-2

Wang, C., and Hashimoto, T. (2018). Self-organization in electrospun polymer solutions: from dissipative structures to ordered fiber structures through fluctuations. Macromolecules 51, 4502-4515. doi: 10.1021/acs.macromol.8b00647

Wang, C., Yin, L., Zhang, L., Xiang, D., and Gao, R. (2010). Metal oxide gas sensors: sensitivity and influencing factors. Sensors 10, 2088-2106. doi: $10.3390 /$ s100302088

Wang, C. Y., Zhang, X., Rong, Q., Hou, N. N., and Yu, H. Q. (2018) Ammonia sensing by closely packed $\mathrm{WO}_{3}$ microspheres with oxygen vacancies. Chemosphere 204, 202-209. doi: 10.1016/j.chemosphere.2018. 04.050

Wang, G., Ling, Y., Wang, H., Yang, X., Wang, C., Zhang, J. Z., et al. (2012). Hydrogen-treated $\mathrm{WO}_{3}$ nanoflakes show enhanced photostability. Energy Environ. Sci. 5, 6180-6187. doi: 10.1039/c2ee03158b

Wang, L., Bi, X., and Yang, S. (2016). Partially single-crystalline mesoporous $\mathrm{Nb}_{2} \mathrm{O}_{5}$ nanosheets in between graphene for ultrafast sodium storage. $A d v$. Mater. 28, 7672-7679. doi: 10.1002/adma.201601723

Wang, M., Fan, L., Wu, X., Tian, D., Cheng, J., Qiu, Y., et al. (2017) Hierarchical mesoporous $\mathrm{SnO}_{2}$ nanosheets on carbon cloth toward enhancing the polysulfides redox for lithium-sulfur batteries. J. Mater. Chem. A 5, 19613-19618. doi: 10.1039/C7TA04937D 
Wang, S., Ang, H. M., Tade, M. O. (2007). Volatile organic compounds in indoor environment and photocatalytic oxidation: state of the art. Environ. Int. 33, 694-705. doi: 10.1016/j.envint.2007.02.011

Wang, W. Q., Wang, X. L., Xia, X. H., Yao, Z. J., Zhong, Y., and Tu, J. P. (2018). Enhanced electrochromic and energy storage performance in mesoporous $\mathrm{WO}_{3}$ film and its application in a bi-functional smart window. Nanoscale 10, 8162-8169. doi: 10.1039/C8NR00790J

Wang, X. D., Summers, C. J., and Wang, Z. L. (2004). Mesoporous single-crystal $\mathrm{ZnO}$ nanowires epitaxially sheathed with $\mathrm{Zn}_{2} \mathrm{SiO}_{4}$. Adv. Mater. 16, 1215-1218. doi: 10.1002/adma.200306505

Wang, Z., Sun, P., Yang, T., Gao, Y., Li, X., Lu, G., et al. (2013). Flowerlike $\mathrm{WO}_{3}$ architectures synthesized via a microwave-assisted method and their gas sensing properties. Sensors Actuators B Chem. 186, 734-740. doi: 10.1016/j.snb.2013.06.015

Xu, K., Ben, L., Li, H., and Huang, X. (2015). Silicon-based nanosheets synthesized by a topochemical reaction for use as anodes for lithium ion batteries. Nano Res. 8, 2654-2662. doi: 10.1007/s12274-015-0772-4

Yamazoe, N., Sakai, G., and Shimanoe, K. (2003). Oxide Semiconductor Gas Sensors. Catalysis Surveys Asia 7, 63-75. doi: 10.1023/A:1023436725457

Yan, S., Xue, J., and Wu, Q. (2018). Synchronous synthesis and sensing performance of $\alpha-\mathrm{Fe}_{2} \mathrm{O}_{3} / \mathrm{SnO}_{2}$ nanofiber heterostructures for conductometric $\mathrm{C}_{2} \mathrm{H}_{5} \mathrm{OH}$ detection. Sensors Actuators B Chem. 275, 322-331. doi: 10.1016/j.snb.2018.07.079

Yang, F., Wang, F., and Guo, Z. (2018). Characteristics of binary $\mathrm{WO}_{3} @ \mathrm{CuO}$ and ternary $\mathrm{WO}_{3} @ \mathrm{PDA} @ \mathrm{CuO}$ based on impressive sensing acetone odor. J. Colloid Interface Sci. 524, 32-41. doi: 10.1016/j.jcis.2018.04.013

Yang, Z., Huang, Y., Yao, F., Luo, H., and Wan, Y. (2018). Wrapping mesoporous $\mathrm{Fe}_{2} \mathrm{O}_{3}$ nanoparticles by reduced graphene oxide: enhancement of cycling stability and capacity of lithium ion batteries by mesoscopic engineering. Ceramics Int. 44, 20656-20663. doi: 10.1016/j.ceramint.2018.08.058

Yin, M., Yu, L., and Liu, S. (2017). Synthesis of Ag quantum dots sensitized $\mathrm{WO}_{3}$ nanosheets and their enhanced acetone sensing properties. Mater. Lett. 186, 66-69. doi: 10.1016/j.matlet.2016.09.083

Yoon, J., Yang, H. S., Lee, B. S., and Yu, W. R. (2018). Recent progress in coaxial electrospinning: new parameters, various structures, and wide applications. Adv. Mater .30:e1704765. doi: 10.1002/adma.201704765

Zhang, D., Zhang, N., Ma, F.-F., Qi, X. D., Yang, J. H., Huang, T., et al. (2018). One-step fabrication of functionalized poly(l-lactide) porous fibers by electrospinning and the adsorption/separation abilities. J. Hazard. Mater. 360, 150-162. doi: 10.1016/j.jhazmat.2018.07.090

Zhang, H., Li, H., Wang, Z., Zheng, Z., Wang, P., Liu, Y., et al. (2018). Fabrication of $\mathrm{BiVO}_{4}$ photoanode consisted of mesoporous nanoparticles with improved bulk charge separation efficiency. Appl. Catalysis B Environ. 238, 586-591. doi: 10.1016/j.apcatb.2018.07.050

Zhang, Q., Zhang, H., Xu, M., Shen, Z., and Wei, Q. (2018). A WO 3 nanorod$\mathrm{Cr}_{2} \mathrm{O}_{3}$ nanoparticle composite for selective gas sensing of 2-butanone. Chin. Chem. Lett. 29, 538-542. doi: 10.1016/j.cclet.2017.09.018
Zhang, X., Dong, Z., Liu, S., Shi, Y., Dong, Y., and Feng, W. (2017). Maize straw-templated hierarchical porous $\mathrm{ZnO}: \mathrm{Ni}$ with enhanced acetone gas sensing properties. Sensors Actuators B Chem. 243, 1224-1230. doi: 10.1016/j.snb.2016.12.076

Zhang, Y., Xu, J., Xiang, Q., Li, H., Pan, Q., and Xu, P. (2009). Brushlike hierarchical $\mathrm{ZnO}$ nanostructures: synthesis, photoluminescence and gas sensor properties. J. Phys. Chem. C 113, 3430-3435. doi: 10.1021/ jp8092258

Zhang, Y., Yue, Q., Yu, L., Yang, X., Hou, X. F., Zhao, D., et al. (2018). Amphiphilic block copolymers directed interface coassembly to construct multifunctional microspheres with magnetic core and monolayer mesoporous aluminosilicate shell. Adv. Mater. 30:1800345. doi: 10.1002/adma.2018 00345

Zhao, T., Luo, W., Deng, Y., Luo, Y., Xu, P., Liu, Y., et al. (2016). Monodisperse mesoporous $\mathrm{TiO}_{2}$ microspheres for dye sensitized solar cells. Nano Energy 26, 16-25. doi: 10.1016/j.nanoen.2016.04.050

Zhao, X., Ji, H., Jia, Q., and Wang, M. (2015). A nanoscale $\mathrm{Co}_{3} \mathrm{O}_{4}$ $\mathrm{WO}_{3}$ p-n junction sensor with enhanced acetone responsivity. Mater. Sci. Mater. Electron. 26, 8217-8223. doi: 10.1007/s10854-0153484-3

Zhao, Y., Dong, F., Han, W., Zhao, H., and Tang, Z. (2019). The synergistic catalytic effect between graphene oxide and three-dimensional ordered mesoporous $\mathrm{Co}_{3} \mathrm{O}_{4}$ nanoparticles for low-temperature $\mathrm{CO}$ oxidation. Microporous Mesoporous Mater. 273, 1-9. doi: 10.1016/j.micromeso. 2018.06.042

Zhou, X., Cheng, X., Zhu, Y., Elzatahry, A. A., Alghamdi, A., Deng, Y., et al. (2018). Ordered porous metal oxide semiconductors for gas sensing. Chin. Chem. Lett. 29, 405-416. doi: 10.1016/j.cclet.2017.06.021

Zhu, L., Zeng, W., and Li, Y. (2018). A novel cactus-like $\mathrm{WO}_{3}-\mathrm{SnO}_{2}$ nanocomposite and its acetone gas sensing properties. Mater. Lett. 231, 5-7. doi: 10.1016/j.matlet.2018.08.007

Zhu, Y., Zhao, Y., Ma, J., Cheng, X., Xie, J., Xu, P., et al. (2017a). Mesoporous tungsten oxides with crystalline framework for highly sensitive and selective detection of foodborne pathogens. J. Am. Chem. Soc. 139, 10365-10373. doi: $10.1021 /$ jacs.7b04221

Conflict of Interest Statement: The authors declare that the research was conducted in the absence of any commercial or financial relationships that could be construed as a potential conflict of interest.

Copyright (c) 2019 Xu, Gao, Li, Zhao, Zhang, Zhao, Wang, Jiang, Zhu, Qian, Fan, Yang and Luo. This is an open-access article distributed under the terms of the Creative Commons Attribution License (CC BY). The use, distribution or reproduction in other forums is permitted, provided the original author(s) and the copyright owner(s) are credited and that the original publication in this journal is cited, in accordance with accepted academic practice. No use, distribution or reproduction is permitted which does not comply with these terms. 